DOI 10.37882/2500-3682.2021.08.09

\title{
ФИГУРНАЯ ПОЭЗИЯ КАК ДИАЛОГ КУЛЬТУР
}

\section{FIGURE POETRY AS DIALOGUE OF CULTURES}

D. Ilgova

Summary: The article analyzes the concept of «figure poetry» as a part of visual poetry. The research traces the history of the origin, development and interaction of figure poems in the historical and cultural paradigm. The article also traces patterns in the use of verbal and visual components in figure poetry of different cultures.

Keywords: visual poetry, figure poetry, baroque, dialogue of culture.
$\mathrm{H}$ есмотря на многообразие существующих форм и достаточное количество исследований в области визуально поэзии, на сегодняшний день отсутствует не только четко установленная классификация визуальной поэзии (хотя попытки осмысления некоторых отдельных форм визуальной поэзии неоднократно принимались, например, Бирюковым [3]), но и четкое определение визуальной поэзии на уровне терминологии.

Среди многообразия трактовок при определении визуальной поэзии, помимо фигурной поэзии [10, с. 321], встречаются также понятия «стихи предметной формы» [14, с. 65-67], «конкретная поэзия» [7, с. 30-32], «фигурные строфы» [6, с. 49-50] и др.

Можно предположить, что возникновение многочисленных определений, происходит из-за того, что визуальную поэзию невозможно полностью отнести к области литературы и исключительно литературоведческого анализа. В отношении визуальной поэзии исследователи, как минимум, призваны обращаться не только к вербальной, текстовой составляющей, но и к визуальной, графической, изобразительной, что дополнительно расширяет область исследования.

В более глобальном подходе изучения визуальной поэзии, на наш взгляд, следует еще более расширить область исследования и опираться на высказанную Бахтиным [1, с. 347-354] теорию о необходимости тесного взаимодействия литературоведения и истории культуры. По мнению Бахтина, литературные произведения следует воспринимать в контексте культурной эпохи, с учетом социальных и экономических факторов, которые могут влиять на литературу посредством культуры.

Следовательно, визуальная поэзия, объединяющая в себе текстовый, вербальный аспект, затем визуальный,

\author{
Ильгова Дарья Алексеевна \\ соискатель, Российский государственный \\ гуманитарный университет, \\ 2. Москва, \\ E-mail:dailgova@yandex.ru
}

Аннотация: Статья посвящена анализу понятия фигурной поэзии как части визуальной поэзии. В работе прослеживается история возникновения, развития и взаимодействия фигурных стихотворений в историко-культурой парадигме. Также в статье прослеживаются закономерности в использовании вербальных и визуальных компонентов в фигурной поэзии разных культур.

Ключевые слова: визуальная поэзия, фигурная поэзия, барокко, диалог культур.

графический, художественный аспект, а также отражающая культурные и социальные тенденции своей эпохи, становится предметом синтеза в искусстве и объектом культурологического анализа.

Под визуальной поэзией мы понимаем определенный вид поэзии, когда внешней форме текста придается особый семантический статус, который подразумевает невозможность целостного восприятия произведения только на основании вербального компонента и без учета визуального компонента.

В данной работе мы обратимся к исследованию фигурной поэзии - типу визуальной поэзии, в основе которого лежит выражение стихотворного текста в виде определенной фигуры.

Если рассматривать фигурную поэзию как объект культурологического анализа, нужно отметить, что возникновение фигурных стихотворений принято связывать с работами древнегреческих поэтов (Симмий Родосский, Феокрит, Досиад) [20, с. 488-510]. Так, например, стихотворения Симмия Родосского, представляли собой простые формы: яйцо или секира. При этом содержание стихотворений соответствовало их внешней форме.

Интерес к необычной форме стихотворений после первых опытов древних греков возникает в эпоху барокко (конец XVI - вторая половина XVIII вв.). Что касается этимологии самого термина «барокко», то среди возможных определений существует отсылка к португальскому прилагательному «barocco», которое использовалось для описания жемчужин неправильной формы [4, c. 741].

И хотя в принято считать, что в первую очередь роскошь и свобода эпохи барокко выражается в расцвете 
живописи и архитектуры. Однако, она не менее полно раскрывается в возникновении фигурных стихотворений, которые в эпоху барокко объединяют в себе поиск и новой формы, и нового содержания.

Основной тематикой для новых визуальных поэтических экспериментов становится переосмысление духовных и религиозных ценностей и догматов. При этом четко прослеживается не только межконфессиональный, но и межкультурный аспект в создании визуальных стихотворений.

Лихачев [9, с. 358-359] отмечает, что в это время русская поэзия обращается к образцам западноевропейской литературы, где широко представлено присущее барокко разнообразие форм и жанров («курьезный» стих, палиндром, «изобразительная эпиграмма», которая предусматривает оформление текста в виде рисунка).

К первым подобным визуальным опытам в России можно отнести молитву Евстратия (рис.1) [2, с. 19-20], написанную в 1621 в виде зигзагообразного рисунка. Сам автор добавил к стихотворению пометку «serpenticum versus», т. е. «серпантинный (или змеиный) стих».

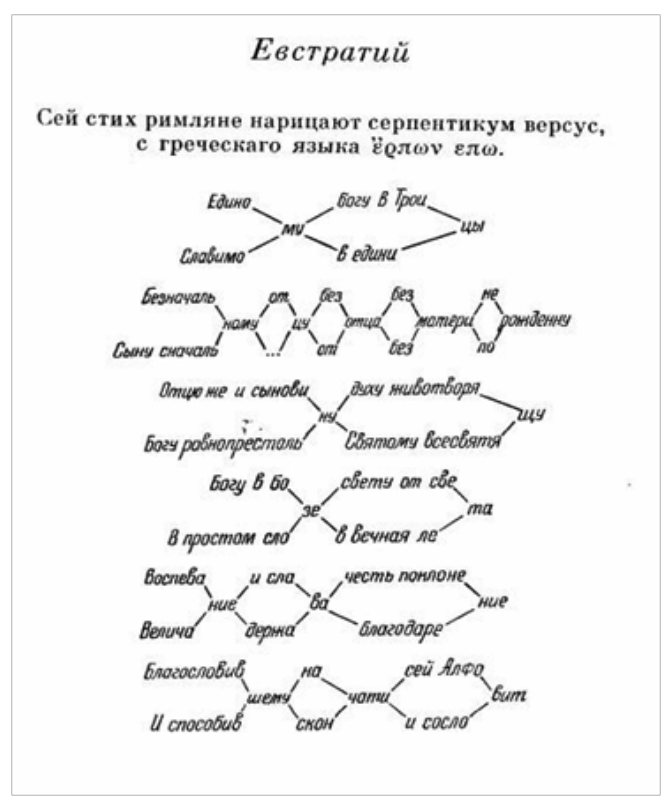

Рис. 1. Евстратий. «Serpenticum versus»

Дальнейшее осмысление религиозной тематики на межкультурном уровне происходит также в виде фигурных стихотворений среди представителей как церковного, так и светского общества. В качестве основных форм для фигурных стихотворений в разных культурах использовались такие религиозные символы, как крест, алтарь, звезда и крылья.

Ярким примером подобного воздействия факторов культуры и религии на визуальную поэзию в XVII вB. могут служить фигурные стихотворения в форме крестов, написанные на разных языках и в разных странах. Например, стихотворение «Крест»/«The Cross» монаха эпохи Средневековья (рис.2) [15] или стихотворение Катарины Регины фон Грейфенберг «О распятом Иисусе» / «Über den gekreuzigten Jesus» (рис.3) [16, с. 403], напечатанное в 1662 году.

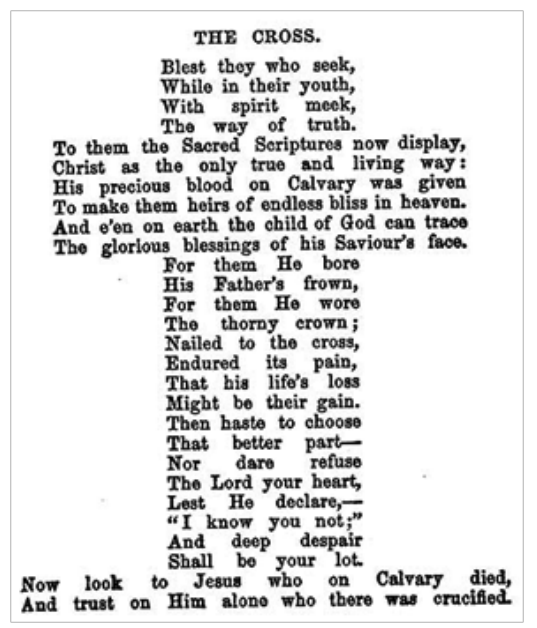

Рис. 2. Монах эпохи Средневековья. Крест

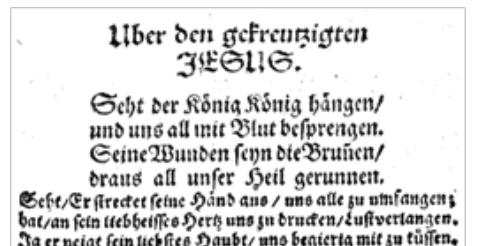

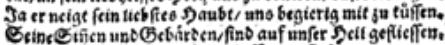

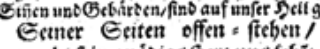

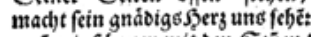

$$
\begin{aligned}
& \text { wain toir fdgauten mit oen Stinen/ } \\
& \text { feben wor uns felbft barinnetr. } \\
& \text { Eo viel Etriemt/fo viel } 23 \text { unoêt } \\
& \text { als an fetnen seib gefunden / } \\
& \text { fo viel Gieg und Eegens - Quellen } \\
& \text { wolt Er unfrer Ecel beftellen. } \\
& \text { trifon Giunel uno oer (ErDen. } \\
& \text { gificen Shinnet und oer croen } \\
& \text { Dolt er aufgeopitert werden: } \\
& \text { bas er (e) } \\
& \text { unte fin fiscente }
\end{aligned}
$$

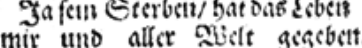

$$
\begin{aligned}
& \text { Tefut Ebrift ! ocin?oo untestmers cts }
\end{aligned}
$$

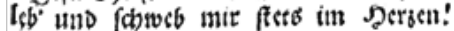

Рис. 3. Катарина Регина фон Грейфенберг. О распятом Иисусе

В русском стихосложении подобным примером является стихотворение Симеона Полоцкого «Крест пречестный церкве слава...» (рис.4 [8, с. 37], рис.5 [12, с. 113]), написанное в 1665 году.

Стоит также обратить внимание на то, что все приведенные выше стихотворения в форме крестов, написанные на английском, немецком и русском языках, легко делятся на строфы, имеют ритмический рисунок и содержат рифмы. При этом содержание данных стихотворений воспринимается в равном положении с формой, 
которая отражает смысл каждого стихотворения.

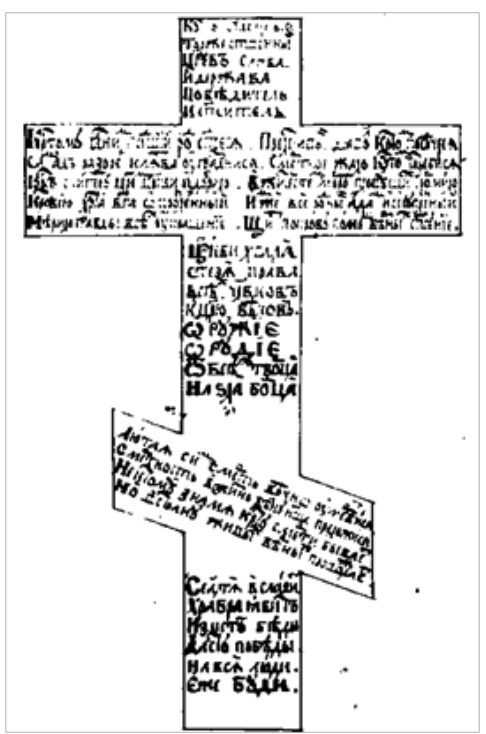

Рис. 4. Симеон Полоцкий. Стихотворение в форме креста

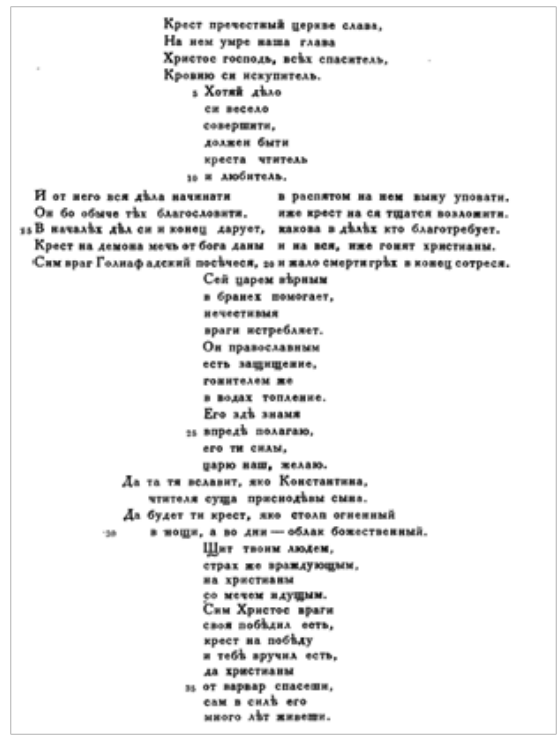

Рис. 5. Симеон Полоцкий.

Стихотворение в форме креста

Еще одной религиозной формой, которая используется в фигурных стихотворениях разных культур, является алтарь. Первые фигурные стихотворения в виде алтаря можно найти у древнегреческих поэтов: «Первый алтарь» Досиада (рис.6) [20, с. 505] и «Алтарь» Луция Юлия Вестина (рис.7) [20, с. 510]. «Алтарь» Досиада отсылает нас к древнегреческой мифологии, а «Алтарь» Луция Юлия Вестина представляет собой монолог от лица самого алтаря. Интересно также отметить, что последний представляет собой акростих, в котором зашифровано послание императору.

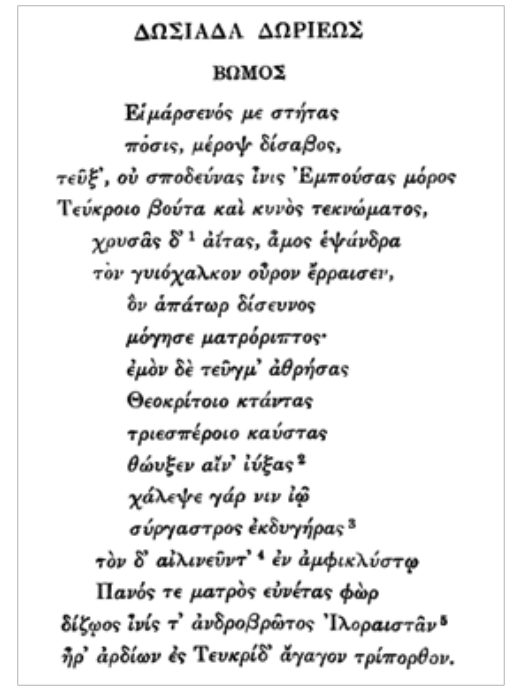

Рис. 6. Досиад. Первый алтарь

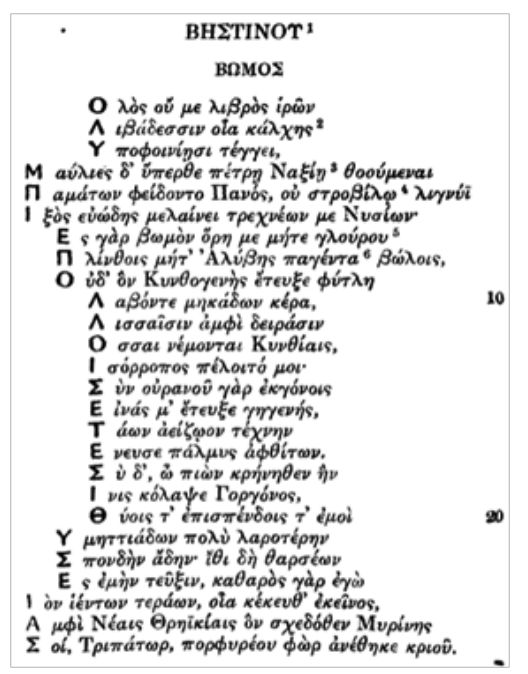

Рис. 7. Луций Юлий Вестин. Второй алтарь

Позднее, в эпоху барокко форма алтаря становится одной из самых популярных форм фигурной поэзии. К ней часто обращаются английские поэты. Например, Роберт Геррик в стихотворении «Столп славы» / «The pillar of fame» (рис.8) [18, с. 100], напечатанном в 1648 году, а также Джордж Герберт в стихотворении «Алтарь» / «The Altar» (рис.9) [17, с. 121], написанном в 1633 году.

Данные стихотворения уходят от прямого высказывания, свойственного более древним образцам, хотя и не теряют связи формы и содержания. В стихотворении «Столп славы» речь идет о своеобразном алтаре памяти, который не смогут поколебать ни природа, ни время.

Стихотворении «Алтарь» Джоржда Герберта тоже метафорично. В нем речь идет не о настоящем алтаре, но об алтаре в сердце героя, который несмотря на тяготы и слезы обращается к богу. 
Ames pillar here, at laft, we fet, Out-during Marble, Braffe, or Jet, Charm'd and enchanted fo, As to withitand the blow Of overthrow :

Nor fhall the feas,

Or Outrages

Of ftorms orebear

What we up-rear,

Tho Kingdoms fal,

This pillar never fhall

Decline or wafte at all;

But ftand for ever by his owne

Firme and well fixt foundation.

Рис. 8. Роберт Геррик. Столп славы

\section{The Altar.}

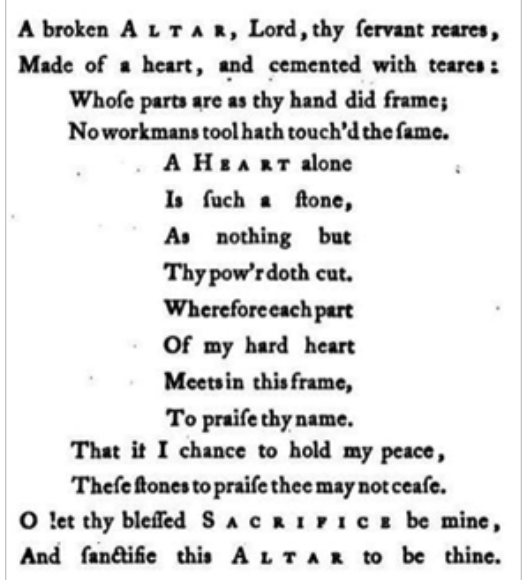

Рис. 9. Джордж Герберт. Алтарь

Не менее интересный феномен представляют собой стихотворения, написанные в форме звезды. В русском стихосложении известно, например, стихотворение Симеона Полоцкого из «Благоприветствования» царю Алексею Михайловичу по случаю рождения царевича Симеона (рис.10) [12, с. 128-129], написанное в форме звезды. Стоит отметить, что это стихотворение отличается от предыдущих образцов фигурных стихов, так как оно написано по принципу лабиринта. Для прочтения необходимо сначала распутать каждую из вершин звезды, распрямить ее в строку. Только после этого можно прочесть стихотворение.

По иному, более классическому с точки зрения фигурной поэзии принципу построено более позднее стихотворение «Звезда» («И кто придя в твои запретныя...») Ивана Рукавишникова, написанное в 1919 году (рис.11) [15]. В нем мы уже видим форму звезды, выстроенную из рифмованных строк.

Рассматривая многообразие фигурных стихотворений, которые были явлены миру в эпоху барокко, мы видим, что фигурные стихотворения древнегреческих поэтов, основные формы которых также использовались в эпоху барокко, были не просто скопированы, но переосмыслены авторами XVII века. В стихотворениях эпохи барокко более ярко выражен личностный аспект, переживания и мольбы конкретного человека, автора.

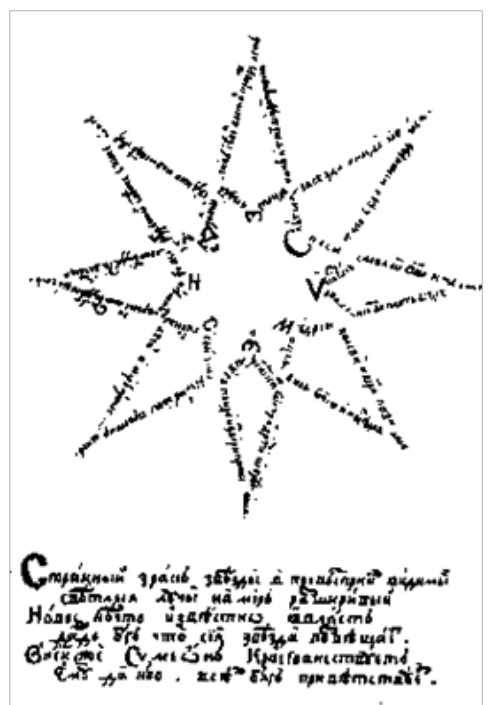

Рис. 10. Симеон Полоцкий. Стихотворение в форме звезды

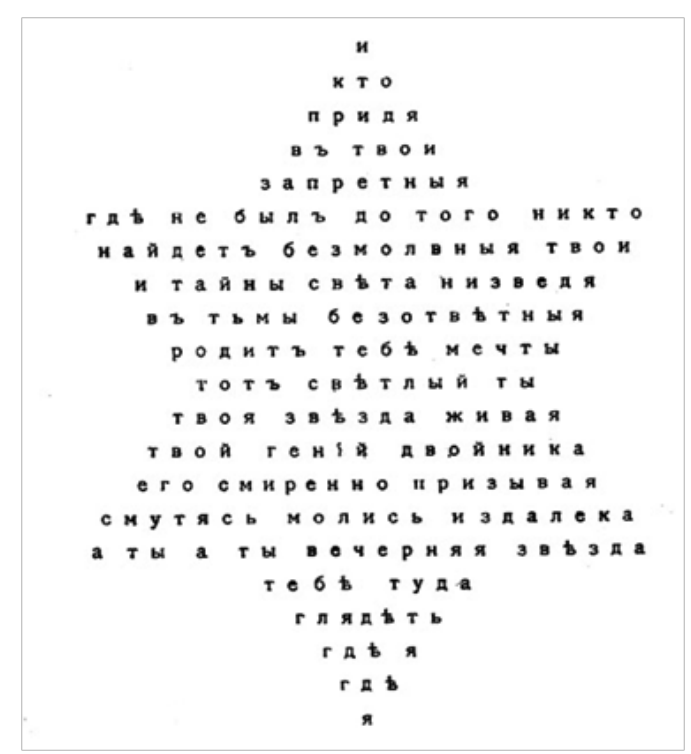

Рис. 11. Иван Рукавишников. Звезда

При этом важным аспектом фигурной поэзии эпохи барокко в разных культурах остается тот факт, что несмотря на сложность внешней формы, рассмотренные нами произведения представляют собой рифмованные стихотворения и имеют ритмический рисунок.

На примере рассмотренных фигурных стихотворений мы можем проследить диалог культур, который, согласно Бахтину, происходит в «большом времени» 
[1, с. 350]: от древнегреческой культуры, представленной Симием Родосским и Досиадом, до западноевропейской, представленной в стихотворениях английских и немецких авторов XVII века, а также русской, представленной фигурными стихотворениями Евстратия и Симеона Полоцкого.

Стоит отметить, что после эпохи барокко мы можем наблюдать некоторое снижение интереса к созданию фигурных стихотворений.

Рассматривая развитие русской фигурной поэзии в XVII-XIX веках, Вишневский [6, с. 50] отмечает только 4 фигурных стихотворения: «Ромб»Ржевского, «Крест» Сумарокова, «Пирамида» и «Надгробие» (вероятно, Вишневский имеет в виду стихотворение «На смерть Суворова») Державина.

Однако, культура и литература эпохи барокко оказала большое влияние на искусство XX века. Лихачев также отмечает существование «многочисленных точек соприкосновения между барокко и современным искусством XX века» [11, с. 175].

Так, в XIX - начале XX века мы еще можем встретить примеры фигурных стихотворений. Однако, стоит обратить внимание на то, что стихотворения этого периода с точки зрения форм выражения тяготеют к простым геометрическим формам. Например, стихотворение «Пирамида» Державина, написанное в 1809 году (рис.12) [13, с. 442] или «Треугольник» Брюсова, написанное в 1918 году (рис.13) [5, с. 524].

С точки зрения теории стихосложения данные образцы фигурных стихотворений еще сохраняют ритмический рисунок и рифмы, но с точки зрения содержания мы уже можем наблюдать отдаление смысла стихотворения от формы его выражения.

\section{СXXVI. ІІИРАМИАА'.}

$$
\begin{gathered}
\text { Зрю } \\
\text { Зарю, } \\
\text { Лучами, } \\
\text { Какъ свьщцами, }
\end{gathered}
$$

Во мракь блестящу,

Въ восторгъ всъ души приводящу.

Но что? - Отъ солнца ль въ ней толь милое блистанье?

Нътъ ! - Пирамида - дъъљъ благихъ воспоминанье.

Рис. 12. Державин Г.Р. Пирамида

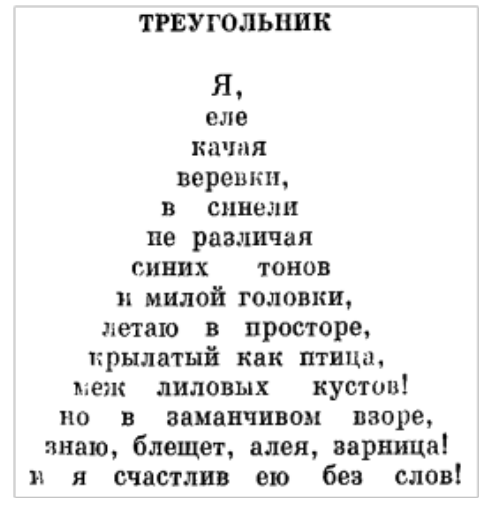

Рис. 13. Брюсов В.Я. Треугольник

Несмотря на распространение новых форм визуальной поэзии в XX веке (например, обширные графические опыты футуристов и символистов), фигурная поэзия продолжает свое развитие и в настоящее время. Образцы фигурной поэзии современности зачастую представляют собой не просто синтез внешней формы и соответствующего содержания, но культурный текст (и соответствующий контекст), позволяющий в полной мере понять высказывание автора, выраженное в фигурном стихотворении.

Например, стихотворение Габриэля Смая «Рекурсивное» (рис.14) [21], опубликованное в 2020 году, представляет собой преобразованную в фигурное стихотворение выдержку об острове Мус Болдер из статьи на Википедии, которая посвящена рекурсивным островам и озерам [22]. Остров Мус Болдер представляет собой географическую матрешку, его расположение наглядно показано на схеме, представленной на рисунке 15. Особенность этого острова состоит в том, что он появляется только в определенные сезоны.

\section{Recursive

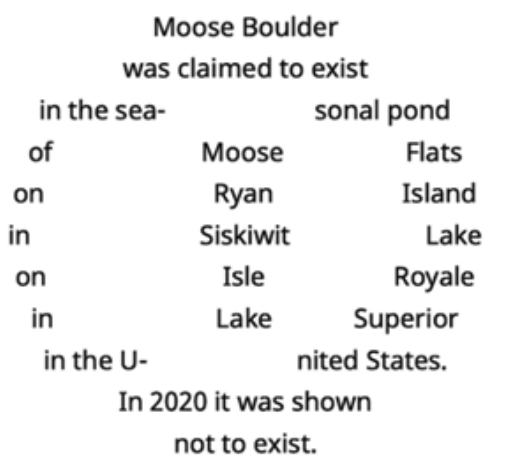

Рис. 14. Габриэль Смай. Рекурсивное 


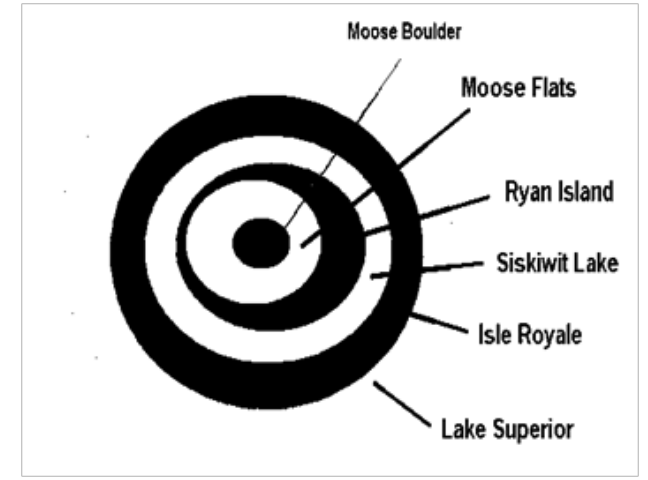

Рис. 15. Расположение острова Мус Болдер

Бруно Латур, анализируя влияние визуального восприятия на современную культуру, писал, что «каждая новая культура визуального по-новому определяет то, что и как мы видим» $[19$, с. 10]. Эта теория в полной мере отражается на истории развития фигурной поэзии, которая в каждую новую культурную эпоху преображала и переосмысляла опыт эпохи предшествующей.
Поясняя концепцию диалога культур и «большого времени» Бахтин отмечал, что «смысловые явления могут существовать в скрытом виде, потенциально и раскрываться только в благоприятных для этого раскрытия смысловых культурных контекстах последующих эпох» [1, c. 351].

Соответственно, можно сказать, что фигурная поэзия эпохи барокко находится внутри диалога культур в «большом времени», где она является центром историко-культурной парадигмы от фигурной поэзии древних греков, которая была переосмыслена в эпоху барокко, до визуальных опытов XX века, возникших также под влиянием эпохи барокко.

Фигурная поэзия эпохи барокко, с одной стороны, выступает в качестве «другой» [1, с. 354] культуры по Бахтину для переосмысления фигурных стихотворений, созданных в древнегреческой культуре, а с другой - служит фундаментом для развития новых форм визуальной поэзии XX века.

1. Бахтин М.М. Эстетика словесного творчества. М: Искусство, 1986.

2. Библиотека литературы Древней Руси / под редакцией Д.С. Лихачева, Л.А. Дмитриева, Н.В. Понырко. СПб.: Наука, 2014. Т.18. 639 с.

3. Бирюков С.Е. Зевгма: Русская поэзия от маньеризма до постмодернизма. М.: Наука, 1994.

4. Большая советская энциклопедия. М: Акционерное общество «Советская энциклопедия», Т.4. 1926.

5. Брюсов В.Я. Собрание сочинений в семи томах. М.: Художественная литература, Т.З. Стихотворения 1918-1924. 1974.

6. Вишневский К.Д. Архитектоника русского стиха XVIII - первой половины XIX века // Исследования по теории стиха. Л.: Наука, 1978.

7. Гаспаров М.Л. Русский стих начала XX века в комментариях. М.: Фортуна Лимитед, 2001.

8. Дуганов Р. Рисунки русских писателей. М.: Советская Россия, 1988.

9. История русской литературы X-XVII веков / Л.А. Дмитриев [и др.]; под редакцией Д.С. Лихачева. М.: Просвещение, 1979. 462 с.

10. К Квятковский А. Поэтический словарь. М.: Советская энциклопедия, 1966.

11. Лихачев Д.С. Развитие русской литературы X-XVII веков. СПб.: Наука, 1998. 204 с.

12. Полоцкий С. Избранные сочинения. Москва-Ленинград: Издательство Академии Наук СССР, 1953.

13. Сочинения Державина с объяснительными примечаниями Я. Грота. Санкт-Петербург: Издание Императорской Академии Наук, Т.З. 1866.

14. Шульговский Н.Н. Занимательное стихосложение. Л.: Издательство «Время», 1926.

15. Ashtray: [сайт]. ULR: http://www.ashtray.ru (дата обращения 01.06.2021)

16. Greiffenberg, Catharina Regina. Geistliche Sonnette / Lieder und Gedichte. Nürnberg 1662.

17. Herbert, George. The English works of George Herbert in six volumes. Edited by George Herbert Palmer. Boston: Houghton, Mifflin and Co., Vol.IIl. 1905.

18. Higgins, Dick. Pattern Poetry: Guide to an Unknown Literature, State University of New York, 1987.

19. Latour B. Visualization and Cognition: Thinking with Eyes and Hands // Knowledge and Society. Vol.6, 1986. P.10.

20. The Greek Bucolic Poets. Translated by Edmonds J.M. Cambridge, MA. Harvard University press, 1912.

21. Verbatim Poetry: [сайт]. ULR: https://verbatimpoetry.com/tag/gabriel-smy/ (дата обращения 01.06.2021)

22. Wikipedia: [сайт].ULR: https://en.wikipedia.org/wiki/Recursive_islands_and_lakes (дата обращения 01.06.2021)

( ) Ильгова Дарья Алексеевна (dailgova@yandex.ru). 